\title{
WILDLIFE MULTISPECIES REMOTE SENSING USING VISIBLE AND THERMAL INFRARED IMAGERY ACQUIRED FROM AN UNMANNED AERIAL VEHICLE (UAV)
}

\author{
L.-P. Chrétien ${ }^{\text {a }}$ J. Théau ${ }^{\text {a }}$, P. Ménard ${ }^{\text {b }}$ \\ ${ }^{\text {a }}$ Dept. of Applied Geomatics, Centre d'applications et de recherches en télédétection (CARTEL), Université de Sherbrooke, Boul. \\ de 1'Université, Sherbrooke, J1K 2R1 CA - (louis-philippe.chretien, jerome.theau)@USherbrooke.ca \\ ${ }^{\mathrm{b}}$ Centre de géomatique du Québec, Jacques-Cartier E. Street, Saguenay, G7H 1Z6 CA - pmenard@cgq.qc.ca
}

KEY WORDS: Wildlife Census, Multispecies Detection, Unmanned Aerial Vehicle, Multicriteria Object-Based Image Analysis, Visible and Thermal Infrared Imagery

\begin{abstract}
:
Wildlife aerial surveys require time and significant resources. Multispecies detection could reduce costs to a single census for species that coexist spatially. Traditional methods are demanding for observers in terms of concentration and are not adapted to multispecies censuses. The processing of multispectral aerial imagery acquired from an unmanned aerial vehicle (UAV) represents a potential solution for multispecies detection. The method used in this study is based on a multicriteria object-based image analysis applied on visible and thermal infrared imagery acquired from a UAV. This project aimed to detect American bison, fallow deer, gray wolves, and elks located in separate enclosures with a known number of individuals. Results showed that all bison and elks were detected without errors, while for deer and wolves, 0-2 individuals per flight line were mistaken with ground elements or undetected. This approach also detected simultaneously and separately the four targeted species even in the presence of other untargeted ones. These results confirm the potential of multispectral imagery acquired from UAV for wildlife census. Its operational application remains limited to small areas related to the current regulations and available technology. Standardization of the workflow will help to reduce time and expertise requirements for such technology.
\end{abstract}

\section{INTRODUCTION}

Precise management of wildlife is often based on population density data (Skalski et al., 2005, Pierce et al., 2012, Williams et al., 2012). Aerial survey is generally used to census large animals over large areas; especially for remote or inaccessible areas (Siniff and Skoog, 1964; Caughley, 1977; Bodie et al., 1995). However, during aerial surveys, observers have to locate, identify, and count wildlife in a very short time (Caughley, 1974). Several methods have been developed to simplify the task for observers such as using several simultaneous observers (Bayliss and Yeomans, 1989; Marsh and Sinclair, 1989; Potvin et al., 1992 Cumberland, 2012), conducting circular flights (Floyd et al., 1979; Stoll et al., 1991; Wiggers and Beckerman, 1993; Havens and Sharp, 1998), and using aerial photography (Garner et al., 1995; Naugle et al., 1996; Haroldson et al., 2003; Israel, 2011; Chabot and Bird, 2012; Franke et al., 2012).

Terrestrial camera traps have been used for multispecies detection for several years but results are presently limited by sampling design and data processing biases (Topler et al., 2008; Ahumada et al., 2013; Burton et al., 2015). Until now, there are no standardized methods to detect several species simultaneously using aerial surveys. Multispecies detection can be useful to study species that coexist spatially in order to reduce survey costs (Bayliss and Yeomans, 1989) and to better understand ecological processes (Burton et al., 2015). However, this practice is too demanding for aerial observers who already need considerable focus to detect single species.

Multispectral aerial imagery is useful for species detection because information is permanently recorded and can be analyzed repeatedly after the census (Terletzky et al., 2012). Furthermore, the use of unmanned aerial vehicles (UAV) to acquire imagery provides very high spatial and temporal resolutions difficult to access with other acquisition platforms (e.g., satellite, airplane, helicopter, etc.) (Eisenbei $\beta$, 2009; Whitehead et al., 2014). Very high spatial resolution provides a high level of details which allows differences in characteristics between species to be distinguished. High temporal resolution allows to conducting censuses in favorable observation windows (i.e., weather, phenology) that can be narrow and highly inconstant.

Until now, very few studies have tested the combined use of UAV, multispectral imagery, and image processing for multispecies detection. This combination was successfully tested on one species by Chrétien et al. (2015). They developed an approach to detect and count white-tailed deer (Odocoileus virginianus) by applying a multicriteria object-based image analysis (MOBIA) on visible and thermal infrared imagery acquired by UAV. Thus, the main objective of the present study was to adapt and evaluate the performance of this approach for detecting and counting simultaneously several large mammal species in a controlled environment.

\section{STUDY SITE}

The study was conducted at the Falardeau Wildlife Observation and Agricultural Interpretive Centre (Centre d'observation de la faune et d'interprétation de l'agriculture de Falardeau) in SaintDavid-de-Falardeau (Québec, Canada). This center welcomes several species of mammals, birds, and reptiles in separate enclosures with a known number of individuals (figure 1). The aim of this project was to detect 4 American bison (Bison bison) including 1 calf, 6 fallow deer (Dama dama), 5 gray wolves (Canis lupus), and 3 elks (Cervus canadensis) (figure 2). The tree vegetation within the enclosures of fallow deer and gray wolves consists mainly of birch (Betula $s p$.). No vegetation is 
present within the enclosures of American bison and elk, except for a few isolated trees.

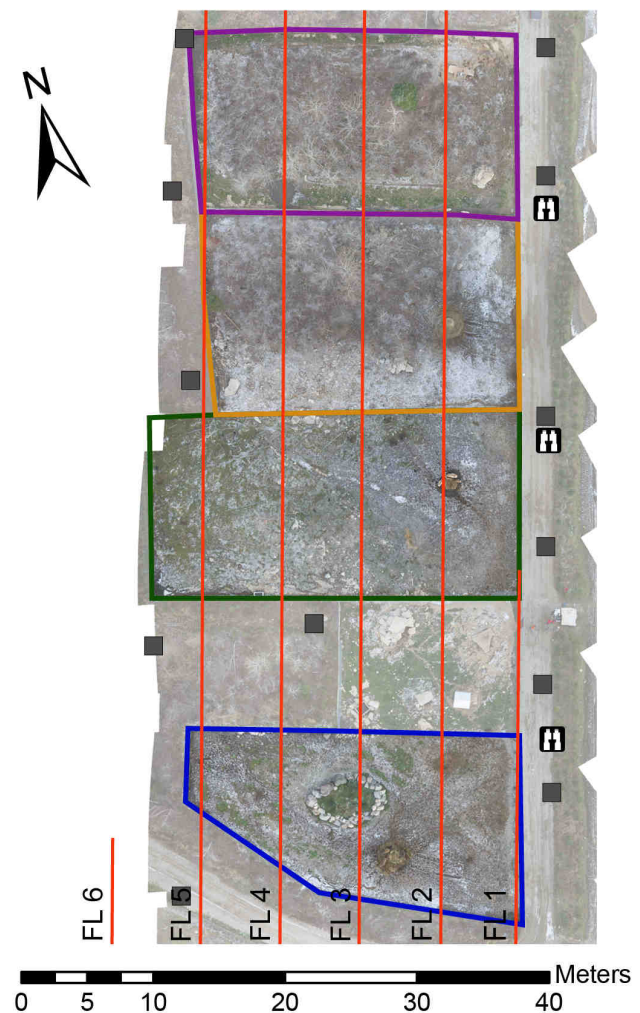

Figure 1. Study area: Enclosures at the Falardeau Wildlife Observation and Agricultural Interpretive Centre in SaintDavid-de-Falardeau, Québec, Canada. Blue enclosure: American bison (Bison bison), Green enclosure: elks (Cervus canadensis), Orange enclosure: fallow deer (Dama dama) and Purple enclosure: grey wolves (Canis lupus). Flight lines (FL; red lines), ground targets $(\square)$ and observers (binocular symbol) are indicated.
A

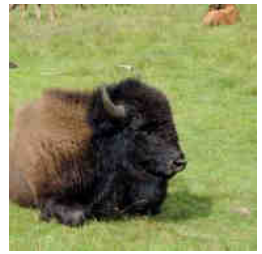

C

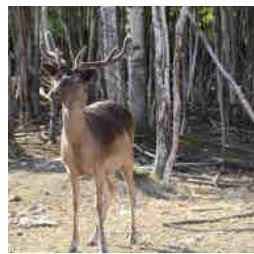

B

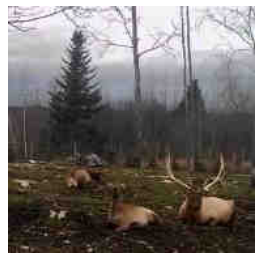

D

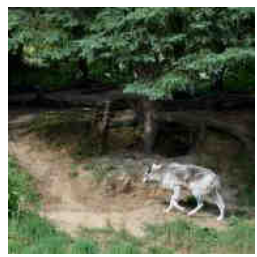

Figure 2. Studied species. A. American bison (Bison bison); B. elks (Cervus canadensis); C. fallow deer (Dama dama); and D. grey wolf (Canis lupus). () L.-P. Chrétien, E. Gavelle

\section{MATERIAL AND METHODS}

\subsection{Data acquisition system}

Data acquisition was performed using a system consisting of a VTOL (vertical take-off and landing) UAV (Responder, ING Robotic Aviation; table 1; figure 3) equipped with the Tau640 (FLIR Systems) and D7000 (Nikon Inc.) sensors (table 2). Visible and thermal infrared images were acquired simultaneously aboard the UAV. The GPS/INS data from the UAV were not available for image georeferencing considering their exclusive use by the autopilot system.

Table 1. UAV specifications and flight limitations

\begin{tabular}{ll}
\hline Specifications & \\
\hline Vehicle type & VTOL helicopter \\
Length & $1328 \mathrm{~mm}$ \\
Height & $408 \mathrm{~mm}$ \\
Main blade length & $690 \mathrm{~mm}$ \\
Main blade diameter & $1562 \mathrm{~mm}$ \\
Tail rotor diameter & $281 \mathrm{~mm}$ \\
Weight (with motor) & $2.83 \mathrm{~kg}$ \\
Flying weight & Max $12 \mathrm{~kg}$ \\
Maximum forward speed & $80 \mathrm{~km} / \mathrm{hr}$ \\
Endurance & Up to 20 minutes \\
Battery & two 6-cell Lithium Polymer \\
IMU accuracy & N/A \\
GPS accuracy & Horizontal : $\pm 2 \mathrm{~m}$ \\
& Vertical : $\pm 1 \mathrm{~m}$ \\
\hline Flight limitations & \\
\hline Maximum wind speed & $30 \mathrm{~km} / \mathrm{hr}$ \\
Minimum visibility & $1600 \mathrm{~m}$ \\
Minimum ceiling & $150 \mathrm{~m}$ AGL \\
Maximum flight altitude & $300 \mathrm{~m} \mathrm{AGL}$ \\
\hline
\end{tabular}

Table 2. Sensors specifications

\begin{tabular}{|c|c|c|}
\hline Specifications & Tau640 & D7000* \\
\hline Sensor type & $\begin{array}{l}\text { Uncooled VOx } \\
\text { microbolometer }\end{array}$ & $\begin{array}{c}\text { Sony IMX071 } \\
\text { CMOS }\end{array}$ \\
\hline Spectral range & $\begin{array}{c}\text { Thermal infrared } \\
(7.5-13.5 \mu \mathrm{m})\end{array}$ & $\begin{array}{c}\text { Visible } \\
(0.40-0.75 \mu \mathrm{m})\end{array}$ \\
\hline Processor & N/A & Expeed 2 \\
\hline Sensor size & $10.88 \times 8.70 \mathrm{~mm}$ & $23.6 \times 15.7 \mathrm{~mm}$ \\
\hline Focal length & $19 \mathrm{~mm}$ & $38 \mathrm{~mm}$ \\
\hline Shutter speed & N/A & $1 / 500-1 / 160$ \\
\hline ISO sensitivity & N/A & 800 \\
\hline Aperture & $f / 1.25$ & $f / 6.3-f / 11$ \\
\hline Field of view $(F o V)$ & $32^{\circ} \times 26^{\circ}$ & $35^{\circ} \times 23^{\circ}$ \\
\hline Size & $44 \times 44 \times 30 \mathrm{~mm}$ & $132 \times 105 \times 166 \mathrm{~mm}$ \\
\hline Weight & $80 \mathrm{~g}$ & $1270 \mathrm{~g}$ \\
\hline Image size & $\begin{array}{c}640 \times 480 \text { pixels } \\
(0.3 \mathrm{MP})\end{array}$ & $\begin{array}{c}4928 \times 3264 \text { pixels } \\
(16 \mathrm{MP})\end{array}$ \\
\hline $\begin{array}{l}\text { Ground sampling } \\
\text { distance (GSD) }{ }^{* *}\end{array}$ & $5.4 \mathrm{~cm} /$ pixel & $0.8 \mathrm{~cm} /$ pixel \\
\hline Radiometric resolution & 8-bit & 12-bit \\
\hline Footprint $^{* *}$ & $34.42 \times 25.82 \mathrm{~m}$ & $37.28 \times 24.69 \mathrm{~m}$ \\
\hline Signal output & $\begin{array}{l}\text { Analog } \\
\text { Digital*** }^{*}\end{array}$ & Digital \\
\hline File format & $\begin{array}{l}\text { ASF (NTSC } \\
30 \mathrm{~Hz} \text { video) }\end{array}$ & NEF/RAW \\
\hline
\end{tabular}




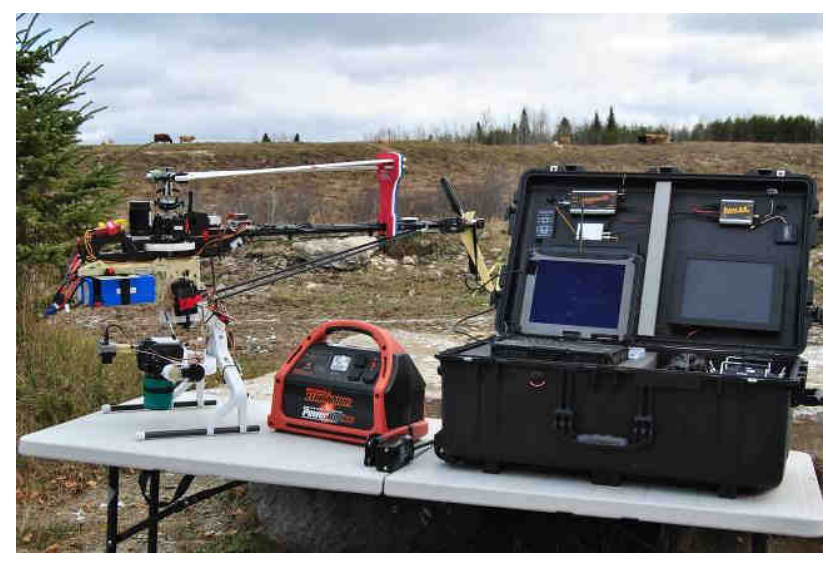

Figure 3. Ground control station and unmanned aerial vehicle used in this study (Responder, ING Robotic Aviation).

\subsection{Data acquisition}

A total of one flight including six flight lines (figure 1) was conducted between 1040 and $1055 \mathrm{hr}$ on 6 November 2012 under a Special Flight Operating Certificate (SFOC) issued by Transport Canada (Reference Number: 5105-01 RDIMS 7899416). During this flight, the altitude above ground level was $60 \mathrm{~m}$ and cruise speeds ranged from 18 to $35 \mathrm{~km} / \mathrm{hr}$ depending on the wind and UAV orientation. The resulting images had a ground sampling distance (GSD) of $0.8 \mathrm{~cm} /$ pixel in the visible and $5.4 \mathrm{~cm} /$ pixel in thermal infrared.

The day before the flight, 22 ground targets were installed in open areas close to access roads (figure 1) and were located using a GeoXH ${ }^{\mathrm{TM}}$ GPS (Trimble) with an accuracy of 10 to 30 $\mathrm{cm}$. These targets were used for imagery georeferencing. Different colors and materials were used for these targets based on their spectral properties in the visible and thermal infrared ranges. Among these targets, 5 of them served as control points to validate that the images were correctly georeferenced.

Ground data observations were collected to validate the detection of animals by the image processing. These data were collected by 3 observers distributed near enclosures (figure 1). Each observer noted the position of each individual during the UAV flight over the enclosure. This information was used to map the position of individuals for comparison with the elements detected by image processing so as to evaluate the performance of the classification.

\subsection{Data processing}

Data preprocessing of visible images and thermal infrared video was performed to obtain a georeferenced mosaic (figure 4; see Chrétien et al. (2015) for more details). A total of 3 flight lines were analyzed over the 6 lines acquired. Three flight lines were rejected due to a position outside the study area (FL1), a lack of overlapping between images (FL5), and a flight interruption due to low batteries (FL6). The other flight lines were mosaicked and analyzed separately and independently in order to reduce detection errors related to potential animal movements between lines.

For each mosaic, a multicriteria object-based image analysis (MOBIA) was performed using eCognition Developer 8.7 (Trimble) according to the following steps:
- multiresolution segmentation (Trimble, 2011) with a scale parameter of 150 , a color/shape and a regularity/compactness of $0.9 / 0.1$ and $0.5 / 0.5$ respectively;

- preclassification based primarily on spectral criteria to detect all potential animals;

- merger of these objects to create superobjets;

- sequential classification to identify each targeted species by adapting at each iteration the species-specific threshold values for the spectral, geometric, and contextual criteria. Elements that have not been assigned to a species were tagged as false positives and excluded after the end of all iterations.

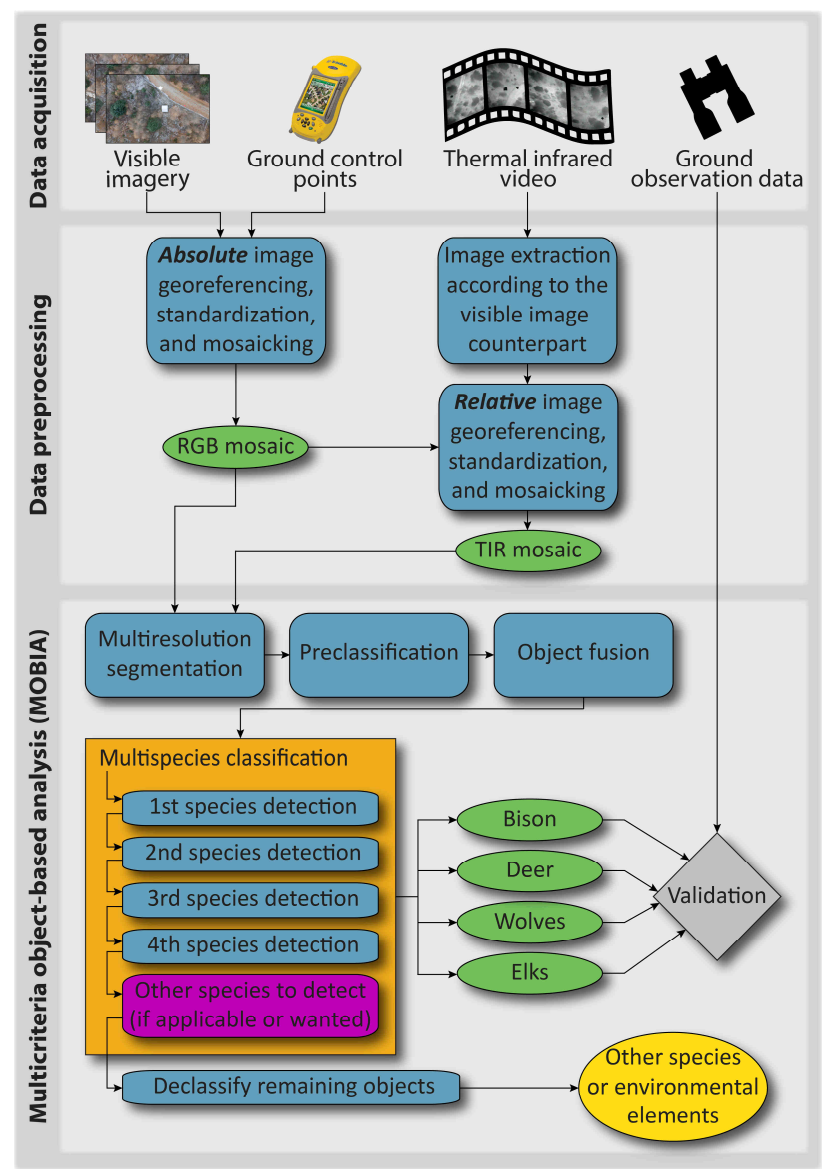

Figure 4. Multispecies detection including data acquisition, preprocessing, and multicriteria object-based image analysis (MOBIA)

Individuals were counted based on the ratio between the size of each area detected and the approximate size of the largest individual recorded in the literature for the targeted species (Nowak, 1999; Feldhamer et al., 2003).

\subsection{Validation of the classification}

For each classification and each species, a binary error matrix with the polygon as the minimum mapping unit was calculated (Congalton and Green, 2009). Validation polygons used for the "species" class came from ground data collected during flights. Polygons for the "non-animal" class were identified by visual interpretation of environmental elements (e.g., deciduous, coniferous, snow, ground targets, feeding troughs, etc.). The validation of the classification was carried out by comparing the dominant class in each polygon (> 50\%) and the class identified in the field. 


\section{RESULTS}

The MOBIA did not perform perfectly to detect and classify all individuals per species (figure 5). Bison and elks were all detected and classified while for fallow deer and wolves, between 0 to 1 individual per flight line was wrongly classified as landscape elements such as bare soil (table 3). Moreover, for fallow deer and wolves, between 0 and 2 individuals per flight line were not detected.
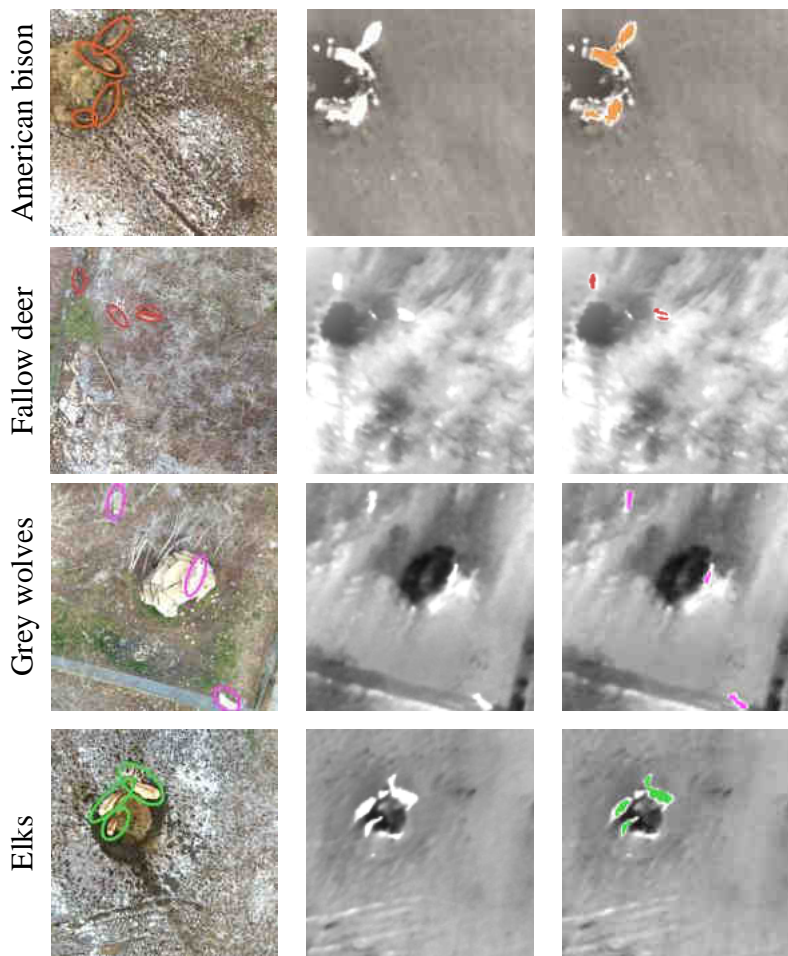

Original visible

\section{Original thermal} infrared
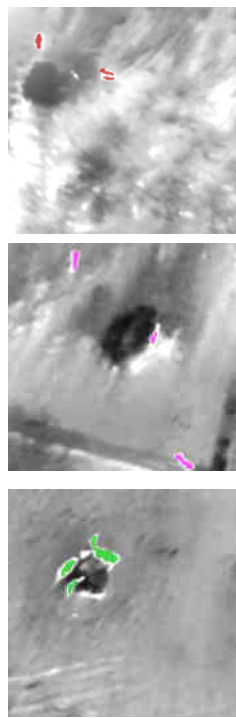

Classification results

Figure 5. Examples of the classification results for the MOBIA with the visible and thermal infrared imagery. Orange. American bison (Bison bison); Red. fallow deer (Dama dama); Magenta. grey wolves (Canis lupus); and Green. elks (Cervus canadensis).
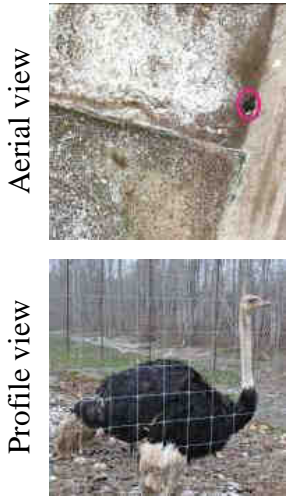

Ostrich
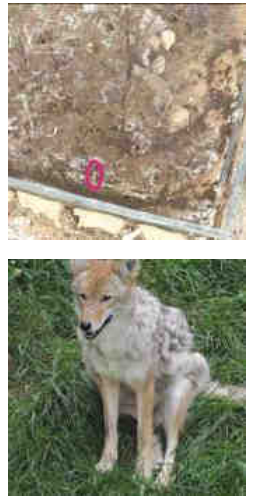

Coyote
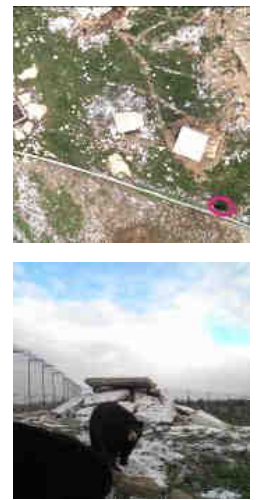

Black bear

Figure 6. Other species present (magenta). Left. ostrich (Struthio camelus); Center. coyote (Canis latrans); and Right. Black bear (Ursus americanus). ( ) L.-P. Chrétien, CGQ

The method has also simultaneously and distinctly detected and classified the four targeted species: 0-3 elks, 0-4 bison, 2-4 wolves, and 2-4 fallow deer per flight line (table 3 ). The results showed no confusion for interspecies identification. Furthermore, other species (i.e., non-targeted species) were present on the acquired images such as 1 ostrich (Struthio camelus), 3 coyotes (Canis latrans), and 3 black bears (Ursus americanus) (figure 6). Since the choices of criteria and parameters have not been selected to specifically identify these species, none of these individuals were classified with the MOBIA.

Table 3. Classification results for each flight line using the MOBIA with the visible and thermal infrared imagery.

\begin{tabular}{cccccc}
\hline Species & $\begin{array}{c}\text { Flight- } \\
\text { Line n }\end{array}$ & Detected $^{1}$ & Real $^{2}$ & Detectable $^{3}$ & Present $^{4}$ \\
\hline \multirow{3}{*}{ Bison } & 2 & 4 & 4 & 4 & 4 \\
& 3 & 4 & 4 & 4 & 4 \\
\hline \multirow{2}{*}{ Fallow } & 4 & 0 & 0 & 0 & 0 \\
deer & 3 & 3 & 2 & 2 & 2 \\
& 4 & 0 & 0 & 2 & 2 \\
Wolves & 3 & 3 & 3 & 4 & 4 \\
\hline \multirow{2}{*}{ Elks } & 4 & 4 & 3 & 3 & 3 \\
& 2 & 3 & 2 & 4 & 4 \\
& 3 & 3 & 3 & 3 & 2 \\
\hline
\end{tabular}

$\overline{{ }^{1} \text { Detected: Number of objects or groups of pixels in the "species" }} \overline{\text { class obtained }}$ following the classification

${ }^{2}$ Real: Number of individuals correctly classified among those detected in (1)

${ }^{3}$ Detectable: Total number of individuals that can be detected in the flight line excluding those that were hidden by the canopy or other visual obstructions

${ }^{4}$ Present: Total number of deer present

\section{DISCUSSION}

\subsection{Image acquisition and preprocessing}

Several factors during the flight campaign affected the quality of the acquired images and their preprocessing. An average wind speed of $19 \mathrm{~km} / \mathrm{hr}$, parallel to flight lines, caused yaw, pitch, and roll movements as well as irregular speed of the UAV. These flight conditions require more work from stabilization mechanisms, which increase the energy consumption. Thus, a decrease of the UAV endurance was observed.

This flight instability due to wind conditions led to an image forward overlap between $5 \%$ and $38 \%$ (figure 7) instead of a theoretical overlap of $57 \%$. This lower performance reduced the ability of image processing procedures to perform an effective image registration. For better results, it is recommended according to Aber et al. (2010) to have a minimum forward overlap of $60 \%$ and $70 \%$ when wind factors are considered.

Finally, these roll, pitch, and yaw effects also had a direct impact on image quality by deflecting sensors from nadir. In this study, yaw effects were prevailing (figure 7). Several methods can correct these complex distortions such as parametric georeferencing using GPS/INS data, geometric correction with ground control point, image stitching, etc. However, most of these methods were unsuccessful or unavailable in this study. The use of a reference mosaic was the only functional option to correct the imagery in this project. 
$N$
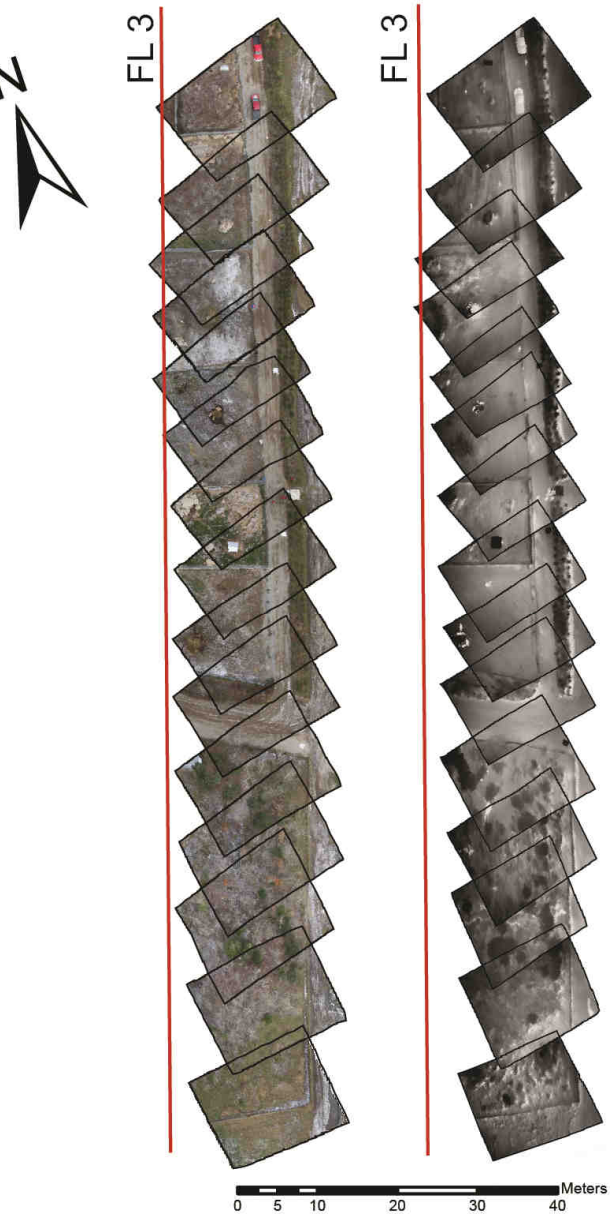

Figure 7. Georeferenced images from flight line $n^{\circ} 3$ (FL 3). Left: visible imagery. Right: thermal infrared imagery.

\subsection{Species analysis}

The MOBIA on visible and thermal infrared imagery was effective for detecting and counting different large mammal species. However, fallow deer and wolves were more difficult to identify than bison and elks. A minimum of four classification criteria using visible characteristics were necessary to identify bison and elks whereas it took 2 and 3 criteria using the visible as well as 6 and 4 additional criteria based on the thermal infrared to identify fallow deer and wolves respectively.

Three factors could explain these results:

(1) Fallow deer and wolves have cryptic fur allowing them to better conceal themselves in their environment than bison and elks. Therefore, they have a higher probability of being confused with the elements of the environment. In this study, deer and wolves were confused in the visible and thermal infrared spectra with rocks. This observation is also supported by Garner et al. (1995), Franke et al. (2012), and Chrétien et al. (2015) who observed that thermal emission of rocks and some parts of the forest floor can be similar to wildlife during clear days.

(2) The body size of animals can also influence their detection rate. Large species are more likely to be detected in comparison with small ones (Caughley, 1974). For example, deer and wolves have an average total length of $1.30-1.75 \mathrm{~m}$ and $1.27-$ $1.64 \mathrm{~m}$ respectively, compared to $2.20-2.50 \mathrm{~m}$ and $2.10-3.90 \mathrm{~m}$ for elks and bison (Nowak, 1999; Feldhamer et al., 2003). Thus, deer and wolves being smaller, they can be harder to detect. No studies have explored the size limits for detecting wildlife. However, Chrétien et al. (2015) showed that spatial resolution of imagery has an impact on the detection rate of white-tailed deer using the MOBIA. This approach was more efficient at very high spatial resolution (i.e., $0.8 \mathrm{~cm}$ ) compared to coarser resolutions. Therefore, considering that the choice of an optimal spatial resolution is related to the body size of animals (Woodcock and Strahler, 1987), it can be hypothesized that the spatial resolution used in this study was suboptimal for the body sizes of fallow deer and wolves.

(3) The detection rate for a species varies depending on the composition of the environment. Wildlife visibility decreases with the increase of vegetation density due to the visual obstruction between individuals and the observer. This could lead to an underestimation of the population size (LeResche and Rausch, 1974; Caughley et al., 1976; Samuel et al., 1987; Bayliss and Yeomans, 1989). In this study, a larger canopy was present in the fallow deer and wolves enclosures compared to bison and elk enclosures. This could explain the lower detection rate obtained for fallow deer and wolves. Some authors (Bayliss and Yeomans, 1989; Franke al., 2012) suggest to define for each species a detection rate for each habitat and to apply a correction factor accordingly. Furthermore, the use of dens by wolves is another element that could affect detection rates of this species; although this situation did not occurred in this study. This underlines the importance of taking into account the ecology of each species before performing a multispecies survey.

These three factors represent research avenues to explore to better understand and control elements that influence the detection rate of each species.

\subsection{Multispecies analysis with the MOBIA}

The MOBIA seems appropriate for multispecies detection of large wildlife. This approach has not only demonstrated its ability to detect multiple species, but also its adaptability to specifically target species of interest for the wildlife manager and to ignore those that are not targeted. Each detected species has its own set of classification thresholds.

The MOBIA approach is more efficient than pixel-based ones to detect wildlife (Chrétien et al., 2015). The cognitive approach used by the MOBIA is based on physical and contextual characteristics of the species (e.g., hue/fur color, thermal contrast with its environment). Thus, an object (or group of pixels) is more informative than a pixel alone because it does not only provide the spectral information, but also the geometric and contextual informations.

Furthermore, unlike pixel-based approaches, the number of individuals present in an image has little or no effect on the MOBIA accuracy due to its sequential approach. It allows for example to indicate the absence of individuals whereas pixelbased approaches usually require training sites (i.e., requiring the presence of individuals) to initiate or finalize the classification process.

Although the MOBIA gave promising results in this project, it would be interesting to test the generalization potential of this approach in a variety of environments and weather conditions. Additionally, this approach should be tested to detect 
taxonomically related species or morphologically similar species (e.g., white-tailed deer and red deer (Cervus elaphus)).

\subsection{Advantages and limitations of image acquisition by UAVs}

UAVs represent a new accessible option to detect and count wildlife. Low altitude operations with manned aircrafts are relatively risky since they leave a small margin of error to the pilot. For wildlife biologists, manned aircraft crashes are the primary cause of work-related death (Wiegman and Taneja, 2003; Jones IV et al., 2006). UAVs can be a safe alternative for the acquisition of census data.

UAVs equipped with autopilots also have the ability to follow flight lines more precisely than manned aircraft (Hodgson et al., 2010) allowing more accurate sampling patterns with straight and parallel flight lines. Separating flight lines by a precise distance between them can avoid double counting of individuals who move between each pass of the aircraft.

Moreover, UAVs have a relatively low noise impact on wildlife (Jones IV et al. 2006, Chabot 2009). It reduces wildlife stress and prevents random behaviors (e.g., escape behaviour) which can cause blurry image acquisitions or errors in animal counting (Bartmann et al., 1986; Wiggers and Beckerman, 1993; Frid, 2003).

The time and costs required to operate UAVs (e.g., material, flight authorization and data acquisition, transportation, flight site preparation, etc.) and to process data can be relatively high. The use of UAVs in remote sensing also requires highly trained personnel to perform UAV operations and image processing. However, this multispecies approach has the potential to standardize and automate the detection and count which will reduce costs in the medium term. Moreover, a rapid technological progress in the fields of UAVs and image processing was observed in the past few years. An increased accessibility of this technology in the future can reasonably be predicted.

The use of UAVs in wildlife studies is facing several limitations. UAVs cannot cover large areas compared to manned aircrafts used for traditional censuses. Three factors are responsible for these limitations: (1) Endurance and flight speed of these devices is limited and can only cover small areas. (2) Canadian regulation restricts flights to visual range. Operating UAVs out of visual range requires sense and avoid technology as well as real time communication with ground control station which is not adapted yet for civil UAVs (Gupta et al., 2013). (3) Data storage space onboard the UAV limits flights to relatively short distances. Advances in the field of onboard data processing and computer vision are expected to reduce these limitations in the short term. This limited coverage area remains very useful to census wildlife by targeting specific areas critical to the ecology of some species (e.g., calving grounds, wintering areas) or to simultaneously census species that coexist spatially (e.g., birds).

As shown in this project, UAVs have some flight restrictions that impact the quality of the acquired data. Improving sensor parameterization is critical to increase the quality of images as well as the use of 3-axis gyro-stabilized gimbals (Aber et al., 2010; Anderson and Gaston, 2013). This system is a rotating support which compensates for angular motions (i.e., roll, pitch, yaw) caused by the movement of the aircraft to maintain a stable angle at nadir (Jones, 2000). This equipment can reduce the effects of deformation and vibration on the images to perform more effective imagery selection and preprocessing.

\section{CONCLUSIONS AND FUTURE WORK}

The multicriteria object-based image analysis using very high spatial resolution visible and thermal infrared images acquired by a UAV is an efficient approach to detecting several species simultaneously. This method also demonstrated its potential to perform the census of a single targeted species using its own specific threshold values. However, more research is needed to improve the detection rate of each species. For example, the use of multiple spectral band combinations needs to be explored. These results open the way for the development of a reproducible and adaptable approach to other species.

This project validates the potential of UAVs to acquire high quality imagery allowing the extraction of census data. However, the current Canadian regulation and the technology limit the coverage of study areas. Applications related to UAVbased imagery will be closely related to UAV regulation and technology developments in the future.

\section{ACKNOWLEDGEMENTS}

This research project was funded by the Fonds de recherche $d u$ Québec - Nature et technologies (FRQNT) and the Natural Sciences and Engineering Research Council of Canada (NSERC) in collaboration with the Centre de géomatique $d u$ Québec (CGQ). The authors also thank the Centre d'observation de la faune et d'interprétation de l'agriculture de Falardeau who kindly provided access to their land where the work was conducted.

\section{REFERENCES}

Aber, J.S., Marzolff, I. and Ries, J.B., 2010. Small-format aerial photography: principles, techniques and geoscience applications. Elsevier, Amsterdam, 268 p.

Ahumada, J.A., Hurtado, J. and Lizcano, D., 2013. Monitoring the status and trends of tropical forest terrestrial vertebrate communities from camera trap data: A tool for conservation. PLOS ONE 8(9), pp. 1-10.

Anderson, K., and Gaston, K.J., 2013. Lightweight unmanned aerial vehicles will revolutionize spatial ecology. Frontiers in Ecology and the Environment 11(3), pp. 138-146.

Bartmann, R.M., Carpenter, L.H., Garrott, R.A. and Bowden, D.C., 1986. Accuracy of helicopter counts of mule deer in Pinyon-Juniper Woodland. Wildlife Society Bulletin 14(4), pp. 356-363.

Bayliss, P., and Yeomans, K.M., 1989. Correcting bias in aerial survey population estimates of feral livestock in Northern Australia using the double-count technique. Journal of Applied Ecology, 26(3), pp. 925-933.

Bodie, W.L., Garton, E.O., Taylor, E.R. and McCoy, M., 1995. A sightability model for bighorn sheep in canyon habitats. The Journal of Wildlife Management, 59(4), pp. 832-840.

Burton, A.C., Neilson, E., Moreira, D., Ladle, A., Steenweg, R., Fisher, J.T., Bayne, E. and Boutin, S., 2015. Wildlife camera 
trapping: a review and recommendations for linking surveys to ecological processes. Journal of Applied Ecology, 52(3), pp. 6 $75-685$

Caughley, G., 1974. Bias in aerial survey. The Journal of Wildlife Management, 38(4), pp. 921-933.

Caughley, G., 1977. Sampling in aerial survey. The Journal of Wildlife Management, 41(4), pp. 605-615.

Caughley, G., Sinclair, R. and Scott-Kemmis, D., 1976. Experiments in aerial survey. The Journal of Wildlife Management, 40(2), pp. 290-300.

Chabot, D., 2009. Systematic evaluation of a stock unmanned aerial vehicle (UAV) system for small-scale wildlife survey applications. Thesis, McGill University, Montreal, Quebec, Canada.

Chabot, D., and Bird, D.M., 2012. Evaluation of an off-theshelf unmanned aircraft system for surveying flocks of geese. Waterbirds, 35(1), pp.170-174.

Chrétien, L.P., Théau, J. and Ménard, P., 2015. Visible and thermal infrared remote sensing for the detection and count of white-tailed deer (Odocoileus virginianus) using an unmanned aerial vehicle. Wildlife Society Bulletin (in revision).

Congalton, R.G. and Green, K., 2009. Assessing the accuracy of remotely sensed data: principles and practices. CRC Press, Boca Raton, 200 p.

Cumberland, R.E., 2012. Potvin double-count aerial surveys in New Brunswick: are results reliable for moose? Alces, 48(1), pp. 67-77.

Eisenbei $\beta$, H., 2009. UAV Photogrammetry. Dissertation, ETH Zurich, Zurich, Switzerland.

Feldhamer, G.A., Thompson, B.C. and Chapman, J.A., 2003. Wild mammals of North America - Biology, management, and conservation. Second edition. The Johns Hopkins University Press, Baltimore, 1216 p.

Floyd, T.J., Mech, L.D. and Nelson, M.E., 1979. An improved method of censuring deer in deciduous-coniferous forests. The Journal of Wildlife Management, 43(1), pp.258-261.

Franke, U., Goll, B., Hohmann, U. and Heurich, M., 2012. Aerial ungulate surveys with a combination of infrared and high-resolution natural colour images. Animal Biodiversity and Conservation, 35(2), pp. 285-293.

Frid, A., 2003. Dall's sheep responses to overflights by helicopter and fixed-wing aircraft. Biological Conservation, 110(3), pp. 387-399.

Garner, D.L., Underwood, H.B. and Porter, W.F., 1995. Use of modern infrared thermography for wildlife population surveys. Environmental Management, 19(2), pp. 233-238.

Gupta, S.G., Ghonge, M.M. and Jawandhiya, P.M., 2013. Review of unmanned aircraft system (UAS). International Journal of Advanced Research in Computer Engineering \& Technology, 2(4), pp. 1646-1658.
Haroldson, B.S., Wiggers, E.P., Beringer, J., Hansen, L.P. and McAninch, J.B., 2003. Evaluation of aerial thermal imaging for detecting white-tailed deer in a deciduous forest environment. Wildlife Society Bulletin, 31(4), pp. 1188-1197.

Havens, K.J. and Sharp, E.J., 1998. Using thermal imagery in the aerial survey of animals. Wildlife Society Bulletin, 26(1), pp. $17-23$.

Hodgson, A., Kelly, N. and Peel, D., 2013. Unmanned aerial vehicles (UAVs) for surveying marine fauna: A dugong case study. Plos One 8(11), pp. 1-15.

Israel, M., 2011. A UAV-based roe deer fawn detection system. In: The International Archives of the Photogrammetry, Remote Sensing and Spatial Information Sciences, Zurich, Switzerland, Vol. XXXVIII-1/C22, pp. 51-55.

Jones, D.I., 2000. Aerial inspection of overhead power lines using video: estimation of image blurring due to vehicle and camera motion. Vision, Image and Signal Processing, IEE Proceedings, 147(2), pp. 157-166.

Jones IV, G.P., Pearlstine, L.G. and Percival, H.F., 2006. An assessment of small unmanned aerial vehicles for wildlife research. Wildlife Society Bulletin, 34(3), pp. 750-758.

LeResche, R.E. and Rausch, R.A., 1974. Accuracy and precision of aerial moose censusing. The Journal of Wildlife Management, 38(2), pp. 175-182.

Marsh, H., and Sinclair, D.F., 1989. Correcting for visibility bias in strip transect aerial surveys of aquatic fauna. The Journal of Wildlife Management, 53(4), pp.1017-1024.

Naugle, D.E., Jenks, J.A. and Kernohan, B.J., 1996. Use of thermal infrared sensing to estimate density of white-tailed deer. Wildlife Society Bulletin, 24(1), pp. 37-43.

Nowak, R.M., 1999. Walker's mammals of the world Volume II. Sixth edition. The Johns Hopkins University Press, Baltimore, $1099 \mathrm{p}$.

Pierce, B.L., R.R. Lopez, and N.J. Silvy. Estimating animal abundance. In: The wildlife techniques manual - Research Volume 1. Seventh edition. The Johns Hopkins University Press, Baltimore, pp. 284-310.

Potvin, F., Breton, L., Rivest, L.P. and Gingras, A., 1992. Application of a double-count aerial survey technique for whitetailed deer, Odocoileus virginianus, on Anticosti Island, Québec. Canadian Field-Naturalist, 106(4), pp. 435-442.

Samuel, M.D., Garton, E.O., Schlegel, M.W. and Carson, R.G., 1987. Visibility bias during aerial surveys of elk in Northcentral Idaho. The Journal of Wildlife Management, 51(3), pp. 622630 .

Siniff, D.B. and Skoog, R.O., 1964. Aerial censusing of caribou using stratified random sampling. The Journal of Wildlife Management, 28(2), pp. 391-401.

Skalski, J.R., Ryding, K.E. and Millspaugh, J.J., 2005. Wildlife demography: Analysis of sex, age, and count data. Academic Press, San Diego, 636 p. 
Stoll Jr, R.J., McClain, M.W., Clem, J.C. and Plageman, T., 1991. Accuracy of helicopter counts of white-tailed deer in Western Ohio farmland. Wildlife Society Bulletin, 19(3), pp. 309-314.

Terletzky, P., Ramsey, R.D. and Neale, C.M.U., 2012. Spectral characteristics of domestic and wild mammals. GIScience \& Remote Sensing, 49(4), pp. 597-608.

Tobler, M.W., Carrillo-Percastegui, S.E., Pitman, R.L., Mares, R. and Powell, G., 2008. An evaluation of camera traps for inventorying large- and medium-sized terrestrial rainforest mammals. Animal Conservation, 11(3), pp. 169-178.

Trimble, 2011. eCognition developer 8.7 - Reference book. Trimble, Munich, Bavaria, Germany.

Whitehead, K., Hugenholtz, C.H., Myshak, S., Brown, O., LeClair, A., Tamminga, A., Barchyn, T.E., Moorman, B. and Eaton, B., 2014. Remote sensing of the environment with small unmanned aircraft systems (UASs), part 2: scientific and commercial applications. Journal of Unmanned Vehicle Systems, 2(3), pp. 86-102.

Wiegman, D. A. and Taneja, N., 2003. Analysis of injuries among pilots involved in fatal general aviation airplane accidents. Accident Analysis and Prevention, 35(4), pp. 571577.

Wiggers, E.P. and Beckerman, S.F., 1993. Use of thermal infrared sensing to survey white-tailed deer populations. Wildlife Society Bulletin, 21(3), pp. 263-268.

Williams, B.K., Nichols, J.D. and Conroy, M.J., 2012. Analysis and management of animal populations - Modeling, estimation, and decision making. Academic Press, San Diego, $817 \mathrm{p}$.

Woodcock, C.E. and Strahler, A.H., 1987. The factor of scale in remote sensing. Remote Sensing of Environment, 21(3), pp. 311-332. 